\title{
CLINICAL AND OPERATIVE ANALYSIS OF 45 UNSUCCESSFULLY OPERATED LUMBAR DISC HERNIATIONS
}

\author{
**Sv. Kalevski, **T. Avramov, **N. Peev, *D. Haritonov, *Pl. Trendafilov \\ *Clinic and **Department of Neurosurgery "St. Anna" District hospital, **Medical university \\ "Prof. d-r Paraskev Stojanov" Varna
}

Reviewed by: Assoc. Prof. St. Djankov, MD, PhD

\section{SUMMARY}

\begin{abstract}
A 341 patients with lumbar disc herniation were operated for a period of 9 years $(1997-2005)$ in the Neurosurgical clinic of Varna. On the postoperative follow-ups 45 of them presented with unsatisfying results. The main factors caused recurrent low back pain were spinal stenosis (central or lateral), residual disc fragments, epidural fibrosis, disc herniation on another level, spinal nerve root damage, infections, psychological or other unknown factors. The results were estimated for a short- and long-term period.
\end{abstract}

Keywords: lumbar disc herniation, recurrent, FBSS, stenosis

\section{INTRODUCTION}

The patients with unsatisfying postoperative results after lumbar discectomy are significant problem and challenge for the modern neurosurgery, with rate between 8 and $30 \%$ according to different actual surveys $(1,2,3,9,11)$. Introduced in this respect term FBSS (failed back surgery syndrome) and often applied as a diagnosis is not always precise because it integrates heterogeneous group in respect of etiology, surgical and nonsurgical factors that cause lasting pain syndrome and neurological symptoms. Identification of the exact reason for FBSS is more and more attainable in the modern spinal surgery, especially with the advent in the last 20 years of the modern neuroimaging (CT, MRT) and also micro neurosurgery $(7,8,9,11)$.

In the present study we make an effort towards analyzing our clinical and operative experience with 45 patients with unsatisfying postoperative results diagnosed prior the operation with lumbar disc herniation. In this cohort we try to identify the commonest surgical reasons that cause FBSS, also to point how to improve the surgical procedures used in this pathology in order to reduce the FBSS cases.

\section{METHODS}

A cohort of 45 patients with unsatisfying postoperative results after surgery for lumbar disc herniation operated for a period of 9 years $(1997$ - 2005). The group comprises patients also patients that are operated for a first time out of the Neurosurgical clinic of Varna, also patients that are op-

Address for correspondence:

Sv. Kalevski, Dept. of Neurosurgery, Medical University, 55 Marin Drinov St, BG-9002 Varna, BULGARIA erated abroad. Of them 29 are men and 16 women, with mean age of 45,6 years, 38 are reoperated once, 5 are reoperated twice, one patient is operated three times and one more than three time. The patients' complaints before the last reoperation are as follows: up to 1 year -29 ; up to 2 years - 11; more than 2 years -5 . Patients' number varies in respect of age as follows: between 20 and 30 years are $6 ; 30$ -40 years $-7 ; 40-50$ years -17 ; over 50 years are 15 . All the patients are diagnosed after thorough clinical examination, conventional X-ray, CT scans, myelography, MRI, EMG etc. Subgroup of 30 patients has complaints that are similar as prior to initial operation, whereas aggravation is registered among 15 patients. The analyzed factors that caused FBSS are presented on table 1:

Tabl. 1 .

\begin{tabular}{||l|c|c||}
\hline \hline & $\mathbf{n}$ & $\mathbf{\%}$ \\
\hline Lateral stenosis & 13 & 29 \\
\hline Retained disc & 7 & 15,5 \\
\hline Epidural fibrosis & 10 & 22,2 \\
\hline $\begin{array}{l}\text { Recurrent disk } \\
\text { herniation or another } \\
\text { level herniation }\end{array}$ & 4 & 8,9 \\
\hline $\begin{array}{l}\text { Nerve root damage } \\
\text { or ruptured dural sac }\end{array}$ & 4 & 8,9 \\
\hline Wound suppuration & 5 & 11,1 \\
\hline Wrong level & 1 & 2,2 \\
\hline Unknown & 1 & 2,2 \\
\hline \hline
\end{tabular}


The initial operative interventions are performed among patients with disc herniations that are allocated as follows (Table 2):

Tabl. 2.

\begin{tabular}{||l|c|c||}
\hline \hline Lateral & level & $\mathbf{n}$ \\
\hline & L4-L5 & 11 \\
\hline Median & Л5-Ec1 & 12 \\
\hline & Л1-Л2 & 1 \\
\hline & Л2-Л3 & 1 \\
\hline & Л3-Л4 & 2 \\
\hline & Л4-Л5 & 8 \\
\hline Two levels & Л5-Ec1 & 5 \\
\hline Three levels & & 4 \\
\hline \hline
\end{tabular}

Depending on the precise preoperative diagnostication 23 laminotomies, 16 interlainotomies and 6 hemilaminectomies have been performed. Stenosis, disc fragments, epidural fibrosis, CSF-fistulas pus-matter etc. have been removed, according to the intraoperative finding. The patients with marked stenosis are treated with one- or two-level foraminotomy, fasetectomy, osteofitectomy and removal of the epidural fibrosis (Fig. 1.)

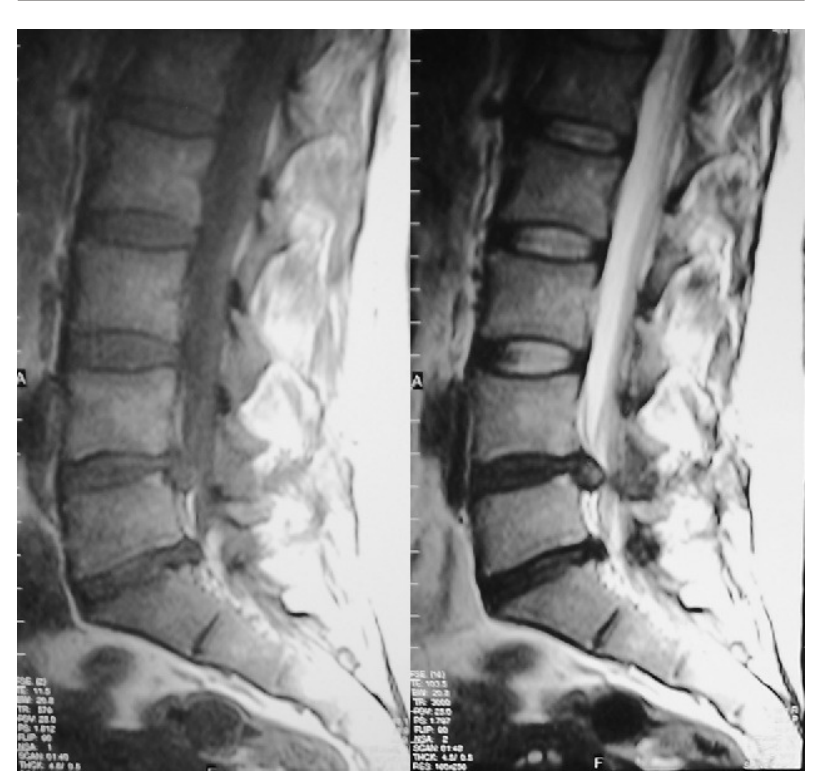

Fig. 1. T2 and T1 weighted MRI images of 30-year patient with persisiting postoperative pain syndrome, that demonstrates left-sided big retained disc fragment on L4-L5 level

\section{RESULTS}

The short-term-follow-ups in respect of the pain syndrome among the reoperated in our clinic patients are allocated a follows (Table 3): 31 of the patients are followed-up for a period of over 2 years (Tabl. 4.).

Tabl. 3.

\begin{tabular}{||l|c||}
\hline & n \\
\hline No pain & 17 \\
\hline Minimal lumbar pain & 7 \\
\hline Significant lumbar pain & 5 \\
\hline Minimal radicular pain & 4 \\
\hline Significant radicular pain & 4 \\
\hline Minimal lumbar and radicular pain & 6 \\
\hline Significant lumbar and radicular pain & 2 \\
\hline \hline
\end{tabular}

Table 4

\begin{tabular}{|l|c|}
\hline \hline & n \\
\hline No complaints & 15 \\
\hline Partial restoration with minimal complaints & 10 \\
\hline Marked neurological dysfunction and pain syndrome & 6 \\
\hline \hline
\end{tabular}

\section{DISCUSSION}

When in 1934 J. Mixter and J.Bar first published operated patient with lumbar disc herniation, they all but suppose what a big door open in the modern lumbar surgery(9). Several years later d-r Mixter itself noted that not all operation performed for the treatment of lumbar disc herniation are successful. Nowadays the introduced as a diagnosis term FBSS is considered as inaccurate because it integrates heterogeneous group of reasons that cause lasting of the pain symptoms among the patients undergone lumbar surgery. Nevertheless SBSS is a matter of extraordinary interest and challenge for the modern neurosurgery. In 1981 Burton CV et al. published a series of a few hundred cases with FBSS, pointing the lateral stenosis as a one of the most significant factors causing FBSS, with rate up to $58 \%$. After this publication a lot of authors published series of reoperated patients with prevalence of recurrent disc herniation and lumbar instability as a reason for FBSS $(4,5$, $6,9,10,11)$. Nowadays authors classify the reasons for FBSS to surgical and non-surgical reasons depending on the therapeuthical approach. We are largely prone to join this group but we abstain from some of the nonsurgical reasons. Insufficient evaluation of the lateral stenosis in our series is a reason for the unsatisfying results in $13-29 \%$ of the cases. Thus we think that this reason, especially when combined with disc prolaps, could be diagnoticated before the operation and should be expected from the surgeon. That is why removal of disc prolaps without attacking foraminal 
stenosis, especially in elderly patients yields unsatisfactory results. Recently we put into practice different fenestrating operative procedures, combined with unilateral or bilateral one- or two-level medial fastectomy, hence we reduce the lateral stenosis as a relative reason for FBSS. Our practical experience suggests that patient who undergo isolated discectomy without foramenotomy and fasetectomy have complaints recidivating a few months, up to year after the operation.

We have found retained disk fragments as a reason for FBSS in $7(15,5 \%)$ of our cases. This is why we stick at the original lumbar discectomy with thorough sweeping of the intervertebral disc space, originally described from Caspar and Lowe in 1978. We have found epidural fibrosis as a reason for lasting pain syndrome in $10(22,25 \%)$ of our cases. Of them 7 have postoperative long-term-follow-up unsatisfactory results, that is why we are prone to agree Slipman et al.(2002), who treat the epidural fibrosis as a non-surgical reason for FBSS. In respect of reducing the probability of formation of postoperative epidural fibrosis we aim to minimal resection of tissues and bone structures, also minimal use of bipolar-coagulation in the immediate proximity of the nerve structures.

We have also studied the so-called jatrogenic factors, which appear to be considerable reason for FBSS - overall of $33,3 \%$ for our cohort. This is mainly suppuration of the operative wound - 5 cases recurrent disc herniation or retained disc - 4 cases, dural or nerve root rupture - 4 cases, wrong level - 1 , etc. It is clear that this subgroup is most important for reducing potential FBSS cases. In conclusion it is worthy to note that lumbar surgery is entity that should be treated with maximum responsibility, patience and diligence and should be practiced by experienced surgeons.

\section{CONCLUSION}

The unsuccessful operative interventions regarding lumbar disc herniation are significant problem in the modern neurosurgery. The number of patients with FBSS could be reduced after adequate preoperative diagnostication and prevention of the probable reasons for persisting pain syndrome. The lateral foraminal stenosis one of the most important reasons for FBSS. The residual disc fragments and epidural fibrosis are also considerable reasons for reoperations. Good operative technique and prevention for the surgical reasons that cause FBSS could provide good outcome in the most of the cases.

\section{REFERENCE}

1. Albeck MJ, Kjaer L, Praestholm J, Vestergaard A, Henriksen O, Gjerris F. Magnetic resonance imaging, computed tomography, and myelography in the diagnosis of recurrent lumbar disc herniation. Acta Neurochir (Wien). 1990; 102 (3-4):122-6.

2. Burton CV, Kirkaldy-Willis WH, Yong-Hing $\mathrm{K}$, Heithoff KB. Causes of failure of surgery on the lumbar spine. Clin Orthop Relat Res. 1981 Jun; (157):191-9.

3. Epstein NE. Surgical management of lumbar stenosis: decompression and indications for fusion.

Neurosurg Focus. 1997 Aug 15;3(2)

4. Frymoyer JW, Donaghy RM. The ruptured intervertebral disc. Follow-up report on the first case fifty years after recognition of the syndrome and its surgical significance. J Bone Joint Surg Am. 1985 Sep; 67(7):1113-6.

5. Frymoyer JW, Hanley E, Howe J, Kuhlmann $\mathrm{D}$, Matteri R. Disc excision and spine fusion in the management of lumbar disc disease. A minimum ten-year followup. Spine. 1978 Mar;3(1):1-6.

6. Frymoyer JW, Matteri RE, Hanley EN, Kuhlmann D, Howe J. Failed lumbar disc surgery requiring second operation. A long-term follow-up study. Spine. 1978 Mar;3(1):7-11.

7. Heilbronner R, Fankhauser H, Schnyder P, de Tribolet N. Computed tomography of the postoperative intervertebral disc and lumbar spinal canal: serial long-term investigation in 19 patients after successful operation for lumbar disc herniation. Neurosurgery. $1991 \mathrm{Jul} ; 29(1): 1-7$.

8. Rankine JJ, Gill KP, Hutchinson CE, Ross ER, Williamson JB. The therapeutic impact of lumbar spine MRI on patients with low back and leg pain. Clin Radiol. 1998 Sep; 53(9):688-93.

9. Slipman CW, Shin CH, Patel RK, Isaac Z, Huston CW, Lipetz JS, Lenrow DA, Braverman DL, Vresilovic EJ Jr. Etiologies of failed back surgery syndrome. Pain Med. 2002 Sep;3(3):200-14; discussion 214-7.

10. Striffeler H, Groger U, Reulen HJ."Standard" microsurgical lumbar discectomy vs. "conservative" microsurgical discectomy. A preliminary study. Acta Neurochir (Wien). 1991;112(1-2):62-4.

11. Waguespack A, Schofferman J, Slosar P, Reynolds J. Etiology of long-term failures of lumbar spine surgery. Pain Med. 2002 Mar;3(1):18-22. 